ing agents, Sinclair's interesting studies of the opposed effects of hydroxyurea and cysteamine in different phases of the cell cycle, and cvidence from Duplan and Fuhrer that mitomycin $\mathrm{C}$ can be considered to be a true radiosensitizer of colony forming mouse bone marrow cells.

With multicellular systems, protection studies are dominant. Pihl and Sannor roview the protective effects of thiols and disulphides in mammals, and Semenov discusses the non-sulphur containing protective agents. This reviow is much shorter than the other four and would have been more valuable had it been expanded. Twelve out of sevonteen papers on multicellular systems describe protective effocts, and the quality of these contributions is uneven, although Sztanyik and Várterèsz make an inter esting attempt to analyse the synergism between the protective actions of $2-\beta$-aminoethylisothiourea (AET) and 5 -methoxytryptarnine in mice. The group of contributed papers on the pharmacology of protective and sensitizing agents is disappointing.

Kaplan gives an admirable and up to date review of the laboratory and elinical use of the halogenated pyrimidine base radiosensitizers, and the contributed papers on clinical uses contain an excellent account by Hoshino, Nagai, Sato, Sano and Watari of the treatment of malignant gliomas by the combined use of antimetabolites, 5-bromodeoxyuridine (BUdR) and fractionated radiotherapy.

The book is handsomely produced, as its price would suggest. As all papers begin on the right hand page, there are some empty pages ( 10 per cent, in fact, are blank or contain only a few lines of references), so that one regrets the ornission of any discussion even more. Most of the papers are clearly written, but there is an onus on the editors of volumes containing contributions from those writing in a language not their own to prevent phrases such as "rephlectory vasomotorial disturbances" appearing in print. The book should be useful to those actively working in this field, but the mixed quality of some of its contents make it a less straightforward choice for a general radiobiology library.

JENNIFER SHEWELL

\section{SEAMEC AND ITS JOURNAL}

\section{The South-East Asian Journal of Tropical Medicine and} Public Health

Vol. 1, No. 1. Quarterly. (Central Coordinating Board for Tropical Medicine and Public Health Project by SEAMEC: 420/6 Rajvithi Road, Bangkok, Thailand, March 1970.) $\$ 6.00$ per volume.

The present trend for closer cooperation between countries belonging to a more or less definable geographical, socioeconomic or cultural region is particularly evident in south-east Asia. In that part of the world seven countries (Indonesia, Laos, Malaysia, Philippines, Singapore, South Vietnam and Thailand) have formed a south-east Asian ministers of education organization (SEAMEC) which has its permanent council in Bangkok under the direction of its secretary-general Professor Chamlong Harinasuta.

In 1966 this body set up a regional scheme of medical and public health research and training through the cooperative effort of existing national centres. The funds are provided jointly by the countries themselves and by the United States government. Several conferences, sominars, postgraduate coursos and an exchange of scientists have been organized under this schome. It is believed that this training programme will be more appro priate and less expensive than sending the nationals of the countries involved to institutes and schools in the western world. 'This should also prevent the brain drain from the developing world to the advanced countries.

Among its many services to the community, SEAMEC has now brought out this new journal on tropical medicino and public health. It contains a foreword by Professor B. G. Maegraith, a statement of the raison d'etre of the journal by Professor A. A. Sandosham, its chief editur, and an outline of the SEAMEC's aims, ways and means by Professor Ch. Harinasuta.

The scientific content of the journal is varied, and the subjects range from parasitology and entomology to planning of undergraduate education in south-east Asia. Among the eighteen scientific papers of this issue, maily are of particular interest. Parasitology sensu lato operis with the recent finding of trypanosomes in Malaysian macaques, their transmission by a local Triatoma and consideration of their infectivity to man. Other subjects are: Brugian filariasis in Thailand, attempts to immunize cats with irradiated larvae of Brugia malayi, leptospirosis in West Malaysia, and immuno-diagnosis of parasitic infections. Other relevant topies comprise the attempt at control of Schistosoma spindale, research on molluscan hosts of Angiostrongylus cantonensis, experimental double and triple infection of snails with larval trematodes, fascioliasis in Thailand, technique of permanent mounting of eggs and larvae of helminths, action of diethylcarbamazine on rats, and a malaria survey on Bougainville Island. Entormology covers the bionomies of Anopheles in the western Pacific and fenthion resistance in Culex fatigans. A study on haemoglobin $\mathrm{B}_{2}$ in West Malaysia, an investigation of nutrition and environment in Iban longhouses in Sarawak, discussion of the use of community health projects for undergraduate medical education and an account of a series of laboratory demonstrations complete this first issue.

One can only admire the initiative, the intelligence and the scientific vigour of the south-east Asian research community gathered under the flag of SEAMEC, and the new journal deserves our best wishes and our active support.

I. J. BRUCE-CHWATT

\section{CRUSTAL DISPLACEMENT}

\section{Time and Place in Orogeny}

Edited by P. E. Kent, G. E. Satterthwaite and A. M. Spencer. (Special publication No. 3.) Pp. viii +311 . (Geological Society of London: London, 1969.) $150 \mathrm{~s}$.

AFTER a century and a half of intensive geological research we are scarcely nearer to a clear assessment of the nature, amount and rate of crustal displacement involved in the evolution of continental areas; this at a time when our knowledge of the displacements within the oceanic crust is progressing by leaps and bounds. It was with the aim of rectifying this situation that the Geological Society of London, together with the Yorkshire Geological Society, invited sixteen authors to present papers at a symposium at Durham in January 1968, entitled. "Displacement within Continents". This volume, the first of a three-fold presentation leading to a synthesis of continental displacement within the later Mesozoic and Tertiary orogenic: belts, presents the sixteen symposium papers in an attempt to review the problems involved and to define the parameters for measuring displacement.

The volume is divided into three sections. The first of these consists of five contributions dealing with the structural analysis of orogenic belts. These papers deal with aspects ranging from the intractable problem of interpreting deep-seated movements from surface structures to improved methods of constructing realistic horizontal sections through regions of complex structure. An important paper dealing with the measurement of strain and displacement difference from a theoretical standpoint suggests practical methods for determining crustal shortening over the entire width of an orogenic belt. The role of palaeomagnetic studies is highlighted in the final paper of this section.

The second section contains three papers concerned with the correlation and dating of orogenic events. A natural bias towards radiometric dating is admirably foiled by a 